\title{
EXPERIMENTAL STUDY ON THE OUT-OF-PLANE BUCKLING STRENGTH OF STEEL ARCHES WITH OPEN CROSS SECTION
}

\author{
By Tsutomu SAKATA* and Tatsuro SAKIMOTO**
}

\begin{abstract}
Experiments for total of 11 specimens are carried out to observe the behavior of elasto-plastic out-of-plane buckling of the arch structures with open cross section which are subjected to uniform vertical load. The effects of several factors on ultimate strength are investigated, that is, slenderness ratios of arch rib, load directions, types of bracing system and braced length ratios. The experimental results are compared with the theoretical ones. In general, the theoretical predictions show good correspondence with the experimental results in ultimate strength and buckling modes and so on. Validity and efficiency of the theoretical procedure are confirmed.

Keywords : arch structure, out-of-plane buckling, ultimate strength, experimental study
\end{abstract}

\section{INTRODUCTION}

Several studies have been reported on the ultimate load-carrying capacities of arch structures which fail by inelastic lateral instability, theoretically ${ }^{(1)}$ and experimentally ${ }^{81}$. But the inelastic lateral buckling strength of arch structures with open cross section which are subjected to uniform vertical load has not been clarified sufficiently. One of the reasons for this is the difficulty to analyze the inelastic torsional behavior of the member with an open profile section.

The purposes of this experimental investigation are to provide the fundamental data concerning the inelastic lateral instability of steel arches with open cross section, and to examine the validity of the theoretical study presented previously by the writers ${ }^{9)}$. Since the ultimate strength of the arch structure may be affected by the residual stress, initial lateral crookedness, the slenderness ratio of the arch rib, the load direction, the arch configuration, the type of the bracing system, the braced length ratio and so on, effects of these factors are discussed herein. The experimental results of specimens are compared with the behaviors predicted by the theoretical computations. The observed ultimate strength are also compared with the predictions obtained from the formula proposed by the writers in Ref. 7) for the ultimate strength of arch structures with closed cross section.

\section{EXPERIMENTAL PROGRAM}

\section{(1) Design of the model arch}

Nominal dimensions of the model arch are determined according to the following conditions:

1) The model arch is a parabolic or circular one with two-hinged end conditions, and its structural

* Member of JSCE, M. Eng., Graduate student of Doctor Course, Kumamoto University (2-39-1 Kurokami Kumamoto, 860)

** Member of JSCE, Dr. Eng., Professor of Civil and Environmental Engineering, Kumamoto University 
Table 1 Nominal Dimensions and Structural Properties of the Model Arch.

\begin{tabular}{|c|c|c|c|c|c|c|c|c|c|c|c|c|c|c|c|}
\hline $\begin{array}{r}\text { Nam } \\
\text { Spec }\end{array}$ & $\begin{array}{l}1 \\
m m\end{array}$ & $\begin{array}{l}\mathrm{L}(\mathrm{Lo}) \\
\mathrm{mm}\end{array}$ & \begin{tabular}{|l|}
$\mathrm{f}$ \\
$\mathrm{mm}$
\end{tabular} & $f / 1$ & $\begin{array}{l}\mathrm{t} \\
\mathrm{mm}\end{array}$ & $\begin{array}{l}\mathrm{b} \\
\mathrm{mm}\end{array}$ & $\begin{array}{l}\mathrm{h} \\
\mathrm{mm}\end{array}$ & $\begin{array}{c}\mathrm{A} \\
\mathrm{cm} 2\end{array}$ & $\begin{array}{l}\mathrm{Ix} \\
\mathrm{cm} 4\end{array}$ & $\begin{array}{l}\mathrm{Iy} \\
\mathrm{Cm} 4\end{array}$ & $\begin{array}{l}\mathrm{Iz} \\
\mathrm{cm} 4\end{array}$ & $\frac{G I x}{E I y}$ & $\frac{E C_{w}}{E^{2} \mathbf{I} \mathbf{y}}$ & $r_{y m}$ & $\mathrm{~L} / \mathrm{r}_{y}$ \\
\hline ies & o & $\begin{array}{l}29 \\
30\end{array}$ & 560 & 20 & & 5 & 36 & 34 & & 5 & .5 & 22 & & 4.8 & 98 \\
\hline $\mathrm{P}-15$ & 800 & $\begin{array}{r}29 \\
30\end{array}$ & 560 & .20 & 6.0 & 85 & 136 & 17.64 & 2.12 & 61.6 & 26.6 & 0.014 & 0.001 & 18.7 & 156 \\
\hline$\overline{\mathrm{P}-1}$ & 2800 & \begin{tabular}{|l}
29 \\
30 \\
30
\end{tabular} & 560 & 0.20 & 6.0 & 110 & 136 & 20.64 & 2.48 & 133.3 & 3.4 & 0.008 & .001 & 25.4 & 15 \\
\hline 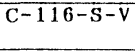 & 2800 & $\begin{array}{r}2840 \\
(3075) \\
\end{array}$ & 560 & 20 & 0 & 110 & 136 & 4 & 48 & 3 & .4 & 08 & 01 & 5.4 & 16 \\
\hline $\begin{array}{r}\bar{P}-296 \\
\quad \text { series } \\
\end{array}$ & 2800 & $\begin{array}{r}2903 \\
(3075) \\
\end{array}$ & 560 & 0.20 & 4.5 & 45 & 79 & .20 & 0.49 & 6.9 & 8.1 & 028 & 0003 & 9.8 & 896 \\
\hline & c & & & & & & & ry & & & & & e c & $\mathrm{y}$ & i \\
\hline
\end{tabular}

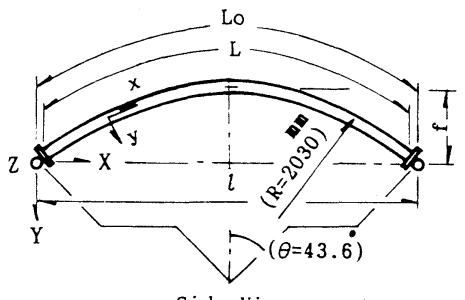

Side-View
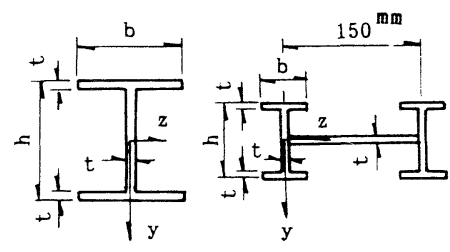

$$
\begin{array}{cc}
\text { Single } & \text { Twin } \\
\text { arch rib } & \text { arch rib }
\end{array}
$$

Cross-Section

Fig. 1 Dimensions of the Model Arch.

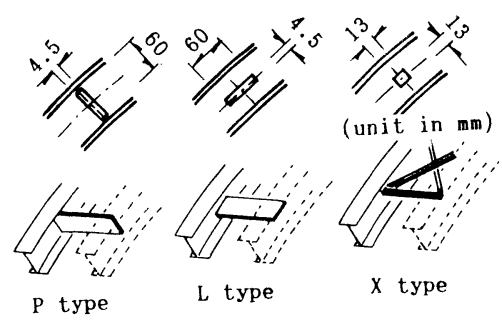

Fig. 2 Dimensions and Arrangements of bracing Members.
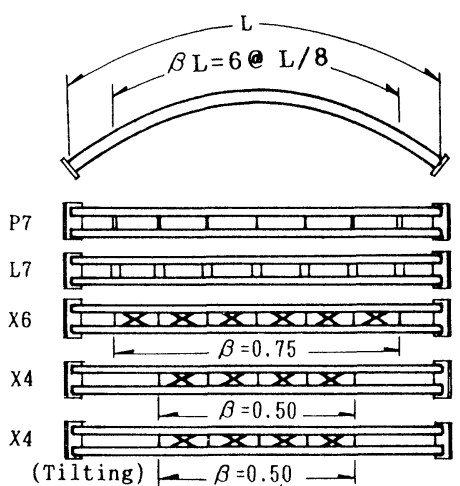

Fig. 3 Bracing System

parameters are similar in proportion to those of existing actual bridges.

2) The slenderness ratio of the arch rib is determined so that the arch fails owing to an overall instability in the elasto-plastic range.

3) The cross section of the arch rib is a welded H-section and its size is large enough to be able to measure accurately the residual stress distribution.

4) The component plates of the cross section should not fail owing to a local buckling prior to the overall instability of the arch.

5) The vertical maximum load must be less than the maximum capacity of an available hydraulic jack, which is 30 tons by itself and 60 tons by using a lever beam.

The nominal dimensions of the model arches are shown in Table 1 and Fig. 1 , where the radius $R$ and the central angle of the arch are defined only for the circular arch.

(2) Lateral bracing members for twin arches

The lateral deformation of the arch is characterized by the interaction between the lateral deflection and the torsional deformation. So, three types of bracing systems, shown in Fig. 2, are designed for specimens 
of twin arches to examine their efficiency. Type $P$, is transverse beams of rectangular cross section and mainly resists torsion of the arch rib. Type L, is also transverse beams of rectangular cross section but mainly resists lateral bending of the arch rib. These two types of transverse beams are just different in the locating direction of the strong axis of the cross section in relation to the arch axis direction as shown in Fig. 2. Type X, consisting of double diagonals in combination with transverse bars, resists lateral bending of the arch as a double warren truss system.

Dimensions of the bracing member of type $\mathrm{P}$ are decided so that it can enhance the torsional rigidity of the
Table 2 List of Test Specimens

\begin{tabular}{|c|c|c|c|c|c|c|}
\hline \multirow[b]{2}{*}{ No. } & \multirow[b]{2}{*}{ Spectimen } & \multirow{2}{*}{$\begin{array}{c}\text { Configu- } \\
\text { ration }\end{array}$} & \multirow{2}{*}{$\begin{array}{l}\text { Slender- } \\
\text { ness ratio }\end{array}$} & \multicolumn{2}{|c|}{ Bracings } & \multirow[b]{2}{*}{ loading } \\
\hline & & & & Type & Number & \\
\hline 1 & $C-116-S-V$ & Circular & 116 & \multirow{6}{*}{\multicolumn{2}{|c|}{ Single Arch }} & \multirow{3}{*}{ Vertical } \\
\hline 2 & $P-115-S-V$ & \multirow{10}{*}{ Parabolic } & 115 & & & \\
\hline 3 & $P-156-S-V$ & & \multirow[t]{2}{*}{156} & & & \\
\hline 4 & $P-156-S-T$ & & & & & Tilting \\
\hline 5 & $P-198-S-V$ & & \multirow[t]{2}{*}{198} & & & Vertical \\
\hline 6 & $P-198-S-T$ & & & & & Tilting \\
\hline 7 & $P-296-P 7-V$ & & \multirow{5}{*}{296} & $\mathrm{P}$ & 7 & \multirow{4}{*}{ Vertical } \\
\hline 8 & $P-296-L 7-V$ & & & L & 7 & \\
\hline 9 & $p-296-x 6-V$ & & & $\mathbf{x}$ & 6 & \\
\hline 10 & $P-296-X 1-V$ & & & $x$ & 4 & \\
\hline 11 & $P-296-X 4-T$ & & & 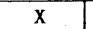 & 4 & Tilting \\
\hline
\end{tabular}

Table 3 Mechanical Properties of the Material

\begin{tabular}{|c|c|c|c|c|c|c|c|}
\hline & $\begin{array}{r}\sigma \mathrm{y} \\
\mathrm{kg} / \mathrm{cm} 2 \\
(\mathrm{MPa})\end{array}$ & $\begin{array}{l}\sigma \mathrm{m} \\
\mathrm{kg} / \mathrm{cm} 2 \\
(\mathrm{MPa})\end{array}$ & $\begin{array}{c}\varepsilon y \\
10-6\end{array}$ & $\begin{array}{l}\text { Est } \\
* 10-6\end{array}$ & $\begin{array}{l}\mathrm{E} \\
\mathrm{kg} / \mathrm{cm} 2 \\
(\mathrm{MPa})\end{array}$ & $\begin{array}{l}\text { Est } \\
\mathrm{kg} / \mathrm{cm} 2 \\
(\mathrm{MPa})\end{array}$ & \begin{tabular}{|c}
$\mathrm{G}$ \\
$\mathrm{kg} / \mathrm{cm} 2$ \\
$(\mathrm{MPa})$
\end{tabular} \\
\hline $\begin{array}{r}\text { Single } \\
\text { Arch } \\
\end{array}$ & $\begin{array}{c}2452 \\
(240.3) \\
\end{array}$ & $\begin{array}{c}3537 \\
(346.6) \\
\end{array}$ & 2100 & 205 & $\begin{array}{l}2130000 \\
(208700) \\
\end{array}$ & $\begin{array}{l}111 \\
(10\end{array}$ & $\begin{array}{l}87 \\
18 \\
\end{array}$ \\
\hline $\begin{array}{l}\text { Twin } \\
\text { Arch }\end{array}$ & $\begin{array}{c}3406 \\
(333.8) \\
\end{array}$ & $\begin{array}{c}4318 \\
(423.2) \\
\end{array}$ & 1900 & 18200 & $\begin{array}{l}2160000 \\
(211700) \\
\end{array}$ & $\begin{array}{l}17900 \\
(1754)\end{array}$ & $\begin{array}{l}855000 \\
(83790)\end{array}$ \\
\hline Remarks & \multicolumn{7}{|c|}{$\begin{array}{l}\sigma y: \text { Yleld stress, } \sigma_{m} \text { :Ultimate strength, Ey:Yield strain } \\
\varepsilon \text { st:Strain-hardening strain, E:Modulus of elasticity } \\
\text { Est:Strain-hardening modulus, G:Shear modulus }\end{array}$} \\
\hline
\end{tabular}

* The varlues given in parentheses indicate SI unit. arch rib, that is, the ratio of the flexural rigidity of the transverse beam, $E I_{b}$, to the torsional rigidity of the single arch rib, $G I_{x}$, is nearly 40 . In the case of type $\mathrm{L}$, the ratio of the flexural rigidity of the transverse beam, $E I_{b}$, to the flexural rigidity of the single arch rib about lateral bending $E I_{a}$, is approximately 1 . In the case of type $X$, the slenderness ratio of the diagonal member is determined to be small enough to avoid its premature buckling prior to the overall failure of the arch. Dimensions of the bracing members are shown in Fig. 2. The arrangement and numbers of the bracing members used are shown in Fig. 3.

\section{(3) Notation of the model}

The names of the specimens are summarized in Table 2. The letters in the notations, for example $\mathrm{P}-296-\mathrm{L} 7-\mathrm{V}$, refer to the configuration ( $\mathrm{P}:$ parabolic, $\mathrm{C}:$ circular), the slenderness ratio of the single arch rib, the type and the number of bracing members and the load direction ( $\mathrm{V}:$ vertical, $\mathrm{T}:$ tilting), in this order. Each specimen is planned to test according to the following intentions:

The slenderness ratios of the single arch models are varied as 198, 156 and 115 to examine the effect on the ultimate strength, and specimens No. 4, No. 6 and No. 11 are prepared to examine the effect of the loading direction (tilting load shown in Fig. 5) on the ultimate strength. The effect of the configuration of arch rib is studied by specimens No. 1 and No.2. The influence of the bracing system on the ultimate strength of twin arch models are studied by specimens No. 7-No. 11. The specimens No. 7 and No. 8 are to observe the effect of the flexural rigidity of transverse beam about the $x$-axis and $y$-axis, (axes are shown in Fig. 1). The braced length ratio $\beta$ is defined as the ratio of the arch rib length braced with lateral members to the total arch rib length. The $\beta$ values of specimens No. 9 and No. 10 are varied as 0.75 and 0.50 , respectively, in order to observe the effect of the braced length ratio $\beta$ on the ultimate strength of twin arch models.

\section{(4) Preliminary tests}

The average values of standard tensile coupon tests are shown in Table 3. The measured values are used for evaluating the model test data. Fig. 4 shows the residual stress distributions obtained from the measured values (by solid lines) and those (by broken lines) modified so as to satisfy the self-equilibrium conditions as well as doubly symmetric conditions. The initial lateral crookedness for each specimen is 

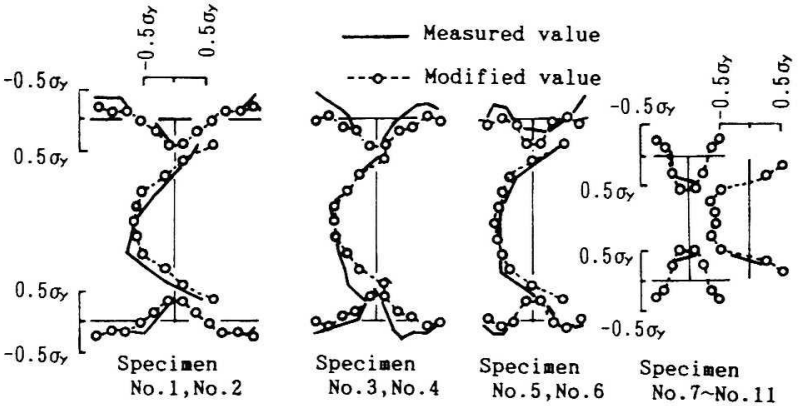

Fig. 4 Residual Stress Distributions.

Table 4 Initial Lateral Crookedness

\begin{tabular}{|c|c|c|c|}
\hline No. & Specimen & Max. Value & Modes \\
\hline 1 & $C-116-S-V$ & $1 / 780$ & \\
\hline 2 & $P-115-S-V$ & $1 / 1080$ & $=$ \\
\hline 3 & $\mathrm{P}-156-\mathrm{S}-\mathrm{V}$ & $1 / 1110$ & $\Longrightarrow$ \\
\hline 4 & $\mathrm{P}-156-\mathrm{S}-\mathrm{T}$ & $1 / 1560$ & 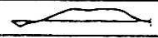 \\
\hline 5 & $P-198-S-V$ & $1 / 2550$ & \\
\hline 6 & $\mathrm{P}-198-\mathrm{S}-\mathrm{T}$ & $1 / 1150$ & \\
\hline 7 & $P-296-P 7-V$ & $\begin{array}{l}\text { N } 1 / 750 \\
\text { S } 1 / 980\end{array}$ & \\
\hline 8 & $P-296-L 7-V$ & $\begin{array}{ll}N & 1 / 1110 \\
S & 1 / 1060\end{array}$ & \\
\hline 9 & $P-296 \times 6-V$ & $\begin{array}{ll} & 1 / 690 \\
S & 1 / 600 \\
\end{array}$ & \\
\hline 10 & $P-296-X 4-V$ & $\begin{array}{l}N 1 / 720 \\
S \quad 1 / 550 \\
\end{array}$ & \\
\hline 11 & $P-296-X 4-T$ & $\begin{array}{l}N \quad 1 / 570 \\
S \quad 1 / 500\end{array}$ & \\
\hline
\end{tabular}

carefully measured after setting the specimen on the test frame. The ratio of the maximum value to the arch span and the shape of the initial lateral crookedness for each specimen are summarized in Table 4.

(5) Application of load

The uniformly distributed vertical load is idealized by a group of eight concentrated loads as shown in Fig. 5 and 6 . The beams installed in the loading apparatus are connected mutually with hinges so as to be free for rotation about both in-plane and out-of-plane directions.

Specimens of which names end with the letter $\mathrm{T}$ were tested under the tilting load condition shown in Fig. 6(b). For these specimens, the lateral displacement of the loading beam is restrained, as shown in Fig. 7, to simulate the actual hanger load in a through-type bridge. Rest of specimens are tested under the vertical load (Fig. 6(a)) which means the case with a flexible deck in actual through-type bridges. The magnitude of the individual concentrated load is checked by wire strain gages mounted on the individual hanger.

(6) Measurements of strains and displacements

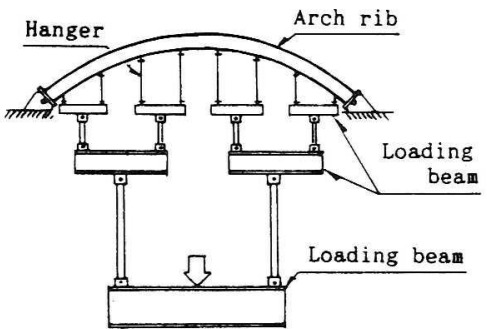

Fig. 5 Loading Apparatus.

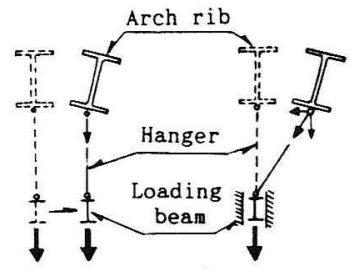

$\begin{array}{rr}\text { (a) Vertical } & \text { (b) Tilting } \\ \text { Load } & \text { Load }\end{array}$

Fig. 6 Load Directions

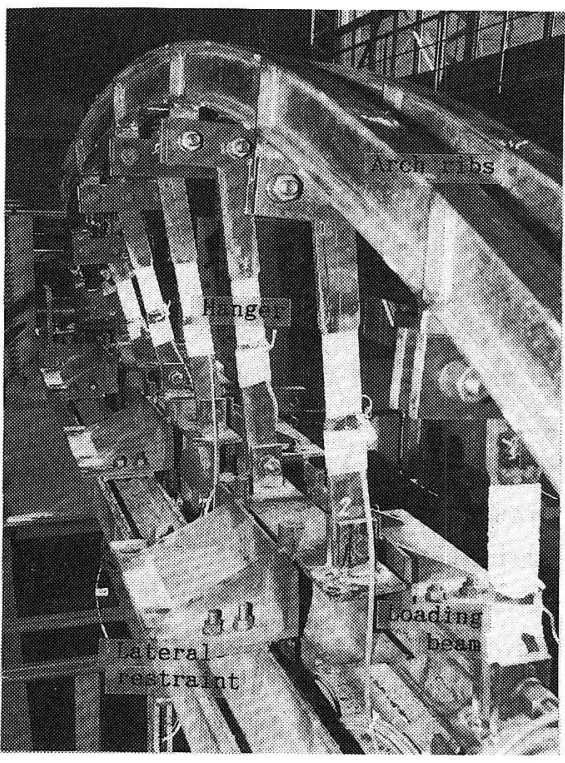

Fig. 7 Lateral Restraint for Loading Beams 
In order to obtain the distribution of the plastic zone and the distribution of strains and stresses over the cross section of the arch rib, sixteen wire strain gages are mounted for single arch specimens at each of five sections, and in the case of twin arches, six wire strain gages for each cross section of which measured values are desired. The lateral and vertical deflections and rotational angle of cross section are measured by a pair of displacement transducers which are located at seven points dividing the arch length into eight equal parts for single arch, and for twin arch specimens two points are added at $L / 16$ and $15 \mathrm{~L} / 16$ points because the large lateral deflections are expected at the unbraced portion.

\section{( 7 ) Test procedures}

At the beginning of each test, the speciment is loaded incrementally to 4 tons in order to confirm the balance of load distribution by the measured strain of hangers, then the load is increased incrementally. In the inelastic range, the incremental load is changed according to the increasing rate of the displacement and all measurements are done after the specimen becomes in equilibrium with the applied load. When the lateral displacement increases excessively without further incremental load, the experiment is finished. Actually, at the maximum load, the specimen is very unstable and out of control under the load by the hydraulic jack. The maximum load for the specimen is defined by the sum of the total applied load and the total weight of the loading beams.

\section{TEST RESULTS}

\section{(1) Theoretical estimation of the ultimate strength of the model arch}

The descriptions for the theory used herein for the numerical analysis of the model arches are available in Ref.9). The computation techniques adopted for the analysis of these model arches are as follows:

1) Since the theory is based on the finite element method, each arch rib is divided longitudinally into 16 member elements for the single arch specimens, 12 member elements for the twin arch specimens having $\mathrm{X}$ type bracing system with braced length ratio 0.50 and 10 member elements for the rest of twin arch specimens, respectively. Each bracing member is treated as one element.

2) In order to trace the growth of the plastic zone, the cross section of the arch rib is also divided into 328 cross-sectional segments (14 divisions in width, 13 in height and 8 layers in the thickness for both flange and web plates) for specimen No. 1 and No.2, 296 (12, 13 and 8, respectively) for specimens No. 3 and No.4, 246 (10, 13 and 8, respectively) for specimens No. 5 and No. 6 and 272 (12, 10 and 8, respectively) for twin arch specimens, respectively. The modified values of the residual stress shown in Fig. 5 are given in each segment as an initial stress.

3) The initial $Z$-coordinate of each nodal point is given so as to be equal to the measured value of initial lateral deflection at the point.

4) The vertical loads are applied to nodes of the arch rib as equivalent nodal forces, and the tilting loads are applied through the hangers restrained laterally at their lower ends.

5) The theoretical maximum load is defined as the average of the last load in equilibrium and the subsequent load at which any corresponding displacement can be no longer found in the incremental approach. The incremental load at the ultimate stage is controlled to be $1 \% \sim 3 \%$ of the theoretical maximum load.

\section{(2) Ultimate strength}

The experimental maximum loads are listed in Table 5 in comparison with the theoretical ones. In this table, $P_{u}$ denotes the maximum vertical load and $N_{u}$ is the ultimate axial force at the springings calculated for the distributed load by a linear theory. The ultimate load carrying capacity is defined by the non-dimensionalized average normal stress $\sigma_{u} / \sigma_{y}=N_{u} / A \sigma_{y}$, in which $A$ denotes the cross-sectional area of the arch rib; $\sigma_{u}$ is the ultimate average normal stress and $\sigma_{y}$ is the yield stress.

In general, the theoretical predictions show fairly good correspondence with the experimental results with exceptions of the specimens No.6, No. 10, No. 11. In specimen No. 6 the theoretical prediction is 


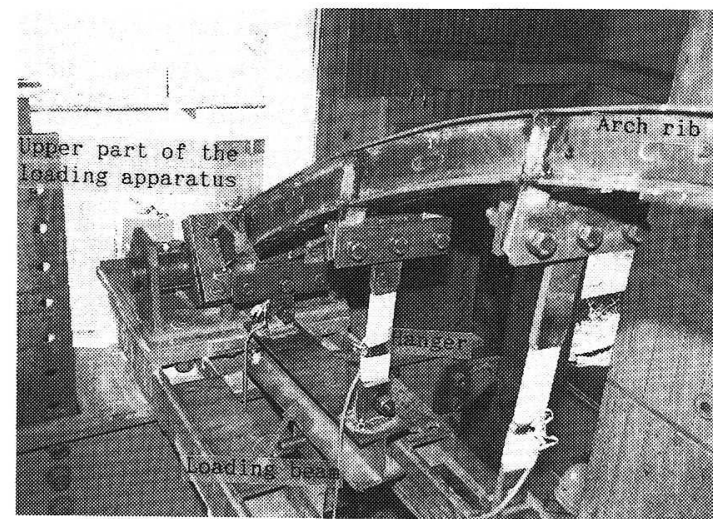

Fig. 8 Upper Part of Loading Apparatus and hangers.

Table 5 Comparison of Maximum Loads.

\begin{tabular}{|c|c|c|c|c|c|c|c|c|c|}
\hline \multirow[b]{2}{*}{ No. } & \multirow[b]{2}{*}{ Specimen } & \multicolumn{2}{|c|}{$\mathrm{Pu}(\mathrm{t})$} & \multicolumn{2}{|c|}{$\mathrm{Nu}(\mathrm{t})$} & \multirow{2}{*}{$\frac{\text { Test }}{\text { Theo. }}$} & \multicolumn{2}{|c|}{$\sigma_{u} / \sigma_{y}$} & \multirow{2}{*}{$\lambda_{y}$} \\
\hline & & Test & Theory & Test & Theory & & Test & Theo. & \\
\hline 1 & $C-116-S-V$ & $\begin{array}{l}49.58 \\
(485.9)\end{array}$ & $\begin{array}{l}49.50 \\
(485.1)\end{array}$ & $\begin{array}{l}39.02 \\
(382.4)\end{array}$ & $\begin{array}{l}38.95 \\
(381.7)\end{array}$ & $\begin{array}{r}100 \\
\%\end{array}$ & 0.823 & 0.821 & 0.606 \\
\hline 2 & $\mathrm{P}-115-\mathrm{S}-\mathrm{V}$ & $\begin{array}{l}43.55 \\
(426.8)\end{array}$ & $\begin{array}{l}47.75 \\
(468.0)\end{array}$ & $\begin{array}{l}34.86 \\
(341.6)\end{array}$ & $\begin{array}{l}38.22 \\
(372.6)\end{array}$ & 91 & 0.740 & 0.812 & .607 \\
\hline 3 & $P-156-S-V$ & $\begin{array}{l}35.48 \\
(347.7) \\
\end{array}$ & $\begin{array}{l}35.75 \\
(350.4) \\
\end{array}$ & $\begin{array}{l}28.40 \\
(278.3)\end{array}$ & $\begin{array}{l}28.61 \\
(280.4) \\
\end{array}$ & 99 & 0.691 & 0.696 & 0.823 \\
\hline 4 & $\mathrm{P}-1$ & \begin{tabular}{|l|}
44.88 \\
$(439.8)$ \\
\end{tabular} & $\begin{array}{l}44.25 \\
(433.7)\end{array}$ & $\begin{array}{l}35.92 \\
(352.0)\end{array}$ & $\begin{array}{l}5.42 \\
(347.1) \\
\end{array}$ & 101 & 370 & 858 & 535 \\
\hline 5 & $\mathrm{P}-198-\mathrm{S}-\mathrm{V}$ & $\begin{array}{l}24.38 \\
(238.9)\end{array}$ & $\begin{array}{l}26.25 \\
(257.3)\end{array}$ & $\begin{array}{l}19.15 \\
(187.7)\end{array}$ & $\begin{array}{l}21.01 \\
(205.9)\end{array}$ & 91 & 0.493 & 0.539 & $\overline{1.073}$ \\
\hline 6 & $\mathrm{P}-198-\mathrm{S}-\mathrm{T}$ & $\begin{array}{l}30.73 \\
(301.2)\end{array}$ & $\begin{array}{l}36.25 \\
(355.3)\end{array}$ & $\begin{array}{l}24.60 \\
(187.7)\end{array}$ & $\begin{array}{l}29.01 \\
(284.3)\end{array}$ & 85 & .640 & 0.755 & 0.690 \\
\hline 7 & $\mathrm{P}-296-\mathrm{P} 7-\mathrm{V}$ & $\begin{array}{l}19.28 \\
(188.9)\end{array}$ & $\begin{array}{l}18.75 \\
(183.8)\end{array}$ & $\begin{array}{l}15.43 \\
(151.2)\end{array}$ & $\begin{array}{l}15.01 \\
(147.1)\end{array}$ & 103 & 0.336 & 0.326 & - \\
\hline 8 & $P-296-L 7-V$ & $\begin{array}{l}41.63 \\
(408.0) \\
\end{array}$ & $\begin{array}{l}44.00 \\
(431.2)\end{array}$ & $\begin{array}{l}33.32 \\
(326.5) \\
\end{array}$ & $\begin{array}{l}35.22 \\
(345.2)\end{array}$ & 95 & 0.731 & 0.773 & - \\
\hline 9 & $P-296-X 6-V$ & $\begin{array}{l}47.13 \\
(461.9)\end{array}$ & $\begin{array}{l}44,25 \\
(433,7)\end{array}$ & $\begin{array}{l}37.72 \\
(369.7) \\
\end{array}$ & $\begin{array}{l}35.42 \\
(347.1)\end{array}$ & 107 & 0.790 & 0.741 & 0.752 \\
\hline 10 & $\mathrm{P}-296-\mathrm{X} 4-\mathrm{V}$ & $\begin{array}{l}35.98 \\
(352.6) \\
\end{array}$ & $\begin{array}{l}29.25 \\
(286.7)\end{array}$ & $\begin{array}{l}28.80 \\
(282.2)\end{array}$ & $\begin{array}{l}23.41 \\
(229.4)\end{array}$ & 123 & 0.607 & 0.493 & 1.170 \\
\hline 11 & $\mathrm{P}-296-\mathrm{X} 4-\mathrm{T}$ & $\begin{array}{l}46.93 \\
(459.9)\end{array}$ & $\begin{array}{l}40.00 \\
(392.0)\end{array}$ & $\begin{array}{l}37.56 \\
(368.1)\end{array}$ & $\begin{array}{l}32.02 \\
(313.8)\end{array}$ & 117 & 0.789 & 0.672 & 0.761 \\
\hline
\end{tabular}

- The values given in parentheses indlcate SI unlt (kN)

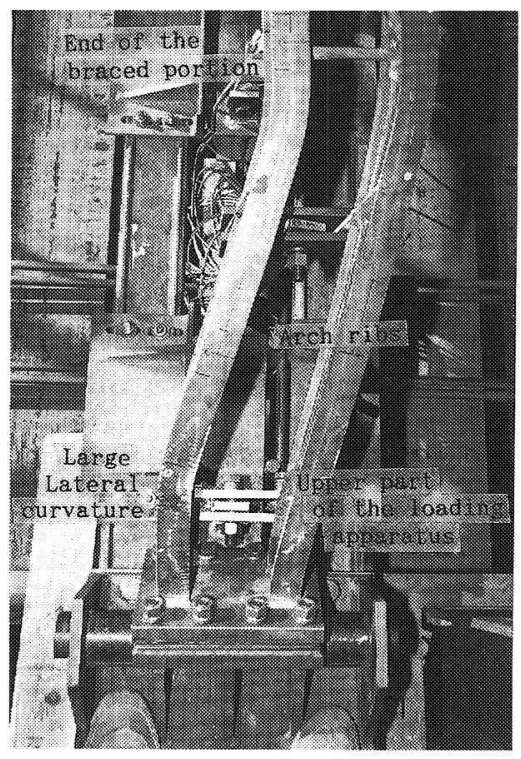

Fig. 9 Lateral Deformation mode at Unbraced Portion (No. 11)

$18 \%$ greater, while in specimens No. 10 , No. 11 the predictions are $20 \%, 15 \%$ less than the experimental values, respectively. Though the cause of the difference between observed and computed values of the ultimate strength in specimen No. 6 can not be found, those in specimens No. 10 and No. 11 can be found in Fig. 9. which shows the lateral deformation mode at unbraced portion of the specimen No. 11. From this figure one can realize that the large lateral curvature of the arch rib is produced at first hanger location. This is suspected to be caused by the restraint given by the upper part of the loading apparatus under the excessive lateral deformation of the arch ribs. As the result, the experimental ultimate strength of these two specimens have shown large values in comparison with computed ones.

\section{(3) The effect of arch configuration}

According to the parametric study for effect of arch configuration and its rise to span ratio $(f / l)$, which are not shown in this paper on account of space consideration, the effect of the arch configuration on the ultimate strength is not appreciable for the arch of which rise to span ratio $f / l<0.2$, but is appreciable for the arch of which rise to span ratio $f / l>0.3$, because of the difference of the in-plane bending moment between the circular arch and parabolic arch.

As for the experimental results, however, the ultimate strength of the circular arch (specimen No. 1) is $10 \%$ greater than the parabolic arch (specimen No. 2). In consideration of the results of parametric study mentioned above, and theoretical results of specimens No. 1 and No.2, it might be thought that the difference in experimental results is not caused by the effect of arch configuration but by some other reason. 


\section{(4) Buckling mode of the arch rib}

The buckling modes of the specimens are shown in Fig. 10, where the maximum lateral displacement is shown by unit length. In this figure, the solid line and broken line represent the modes obtained from experiment and from computation, respectively. As shown in Fig. 10, the correspondence between measured and computed values is fairly good. It is also shown that the theoretical values can follow the asymmetric shape of the measured lateral deflection caused by the asymmetric initial deflection.

In the case of the single arch specimen, the mode of lateral deflection is similar to the buckling mode of the clamped-clamped column, but the torsional deformations of arch rib at the portion near the both ends show the opposite sign to that observed at the arch crown as shown in Fig. 10 (a) ${ }^{10}$. In the case of the specimen of twin arches having the bracing system, the lateral buckling modes are classified into two groups. That is, cases No. 7 and 8 show a similar mode to that of the single arch specimen, and cases No.9, 10 and 11 show another type of mode where most of the lateral deformations are produced at the unbraced portion.

\section{(5) Effect of the load direction}

Experimental results for the relationship between the load and lateral deflection at the crown of single arch rib are shown in Fig. 11. It can be seen from this figure that the ultimate strength of the arch subjected to the tilting hanger load is quite large comparing with the case of the vertical load. The reason is that a tilting hanger produces a restoring lateral force which has stabilizing effect on lateral buckling of the arch as shown in the inset of Fig. 11.

As is clear from what mentioned above, the effect of load direction is also very significant for the lateral buckling strength of arch bridges and the effect depends on the degree of lateral restraint of the loading beam in experiment, while for actual arch bridges of through-type it depends on the lateral flexural rigidity of the floor girder system ${ }^{7}$.

\section{(6) Effect of the type of bracing system}

Since the St. Venant torsional rigidity of thin-walled member with open cross section is much smaller than that of a member with closed cross section, there was a possibility that the contribution rate of the bracing system type-P which mainly resists torsion of the arch rib might come close or superior to that of the bracing system type-L for the arch model with open profile ribs. In order to examine the effect of bracing system on increase in ultimate strength, the experimental results of specimen No. 7 (bracing type P 7) and No. 8 (bracing type L 7) are compared with the theoretical result of single arch whose cross section is the one of twin arch ribs. The load versus lateral displacement curves at crown for these models are shown in Fig. 12. From this figure, the ultimate strength of specimen No. 7 (P 7) is 1.4 times and specimen No. 8 (L 7) is 3.0 times greater than that of single arch rib. That is, the

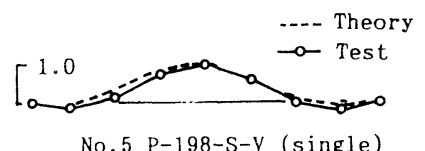

(a) Torsional deformation

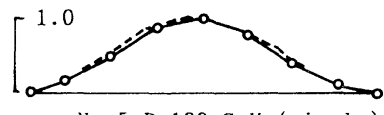

No. 5 P-198-S-V (single)

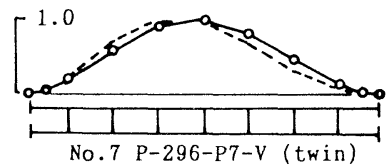

1.0

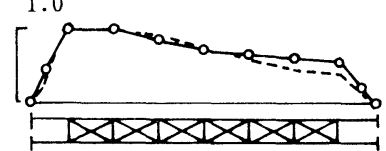

No. 9 P-296-X6-V (twin)

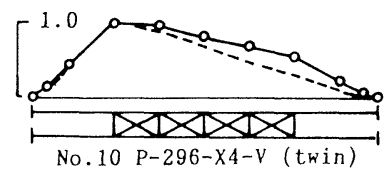

(b) Lateral Deflection

Fig. 10 Modes of Lateral Deformations of Arch Ribs.

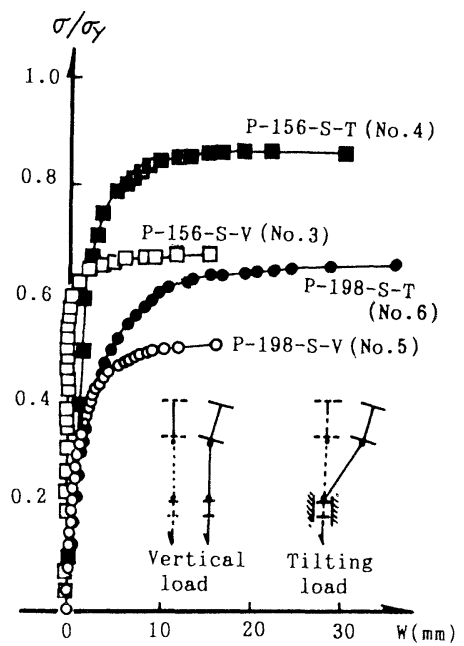

Fig. 11 Load versus Lateral Deflection Curves (Single arch). 
bracing system which resists the lateral bending of arch ribs (type $\mathrm{L}$ ) is more effective for increasing the ultimate strength than that (type $\mathrm{P}$ ) which resists the torsion of arch ribs, even in the arch system with open profile ribs. Since type $\mathrm{X}$ is more effective system than type $\mathrm{L}$ for resisting the lateral bending, it can be confirmed from Fig. 12 that the type $\mathrm{X}$ is the most efficient bracing system. Anyway, it is clear from what mentioned above that the ultimate strength of twin arches is affected considerably by the type of bracing system.

\section{(7) Effect of the braced length ratio}

The effect of braced length ratio $\beta$ on the ultimate strength of arch can be observed by comparing the results of the specimen No. 9 (bracing type X 6) with those of the specimen No. 10 (bracing type X 4 V), because these two specimens are tested under the same condition except the braced length ratio $\beta$ and inevitable initial lateral crookedness. According to the experimental results (Fig. 12), the ultimate strength of specimen No. $9(\beta=0.75)$ is $30 \%$ greater than that of specimen No. $10(\beta=0.50)$. In the case of bracing type $X$, when we assume that the arch ribs are connected rigidly by the bracing members, the moment inertia of cross section of the twin arch ribs about lateral bending at the braced portion can be determined by $I_{y}=2 I_{0}+2 A(a / 2)^{2}$, while at the unbraced portion $I_{y}=2 I_{0}$, where $I_{0}$ denotes the moment inertia of cross section of a single arch rib, $a$ is the distance between twin arch ribs and $A$ is the cross sectional area of a single arch rib.

Since the lateral bending stiffness of the twin arch ribs at the braced portion is much larger than that at the unbraced portion, most of the lateral deflection of arch rib are produced by the deformation at the unbraced portion as shown in Fig. 10. These facts mean that the ultimate strength of the through type arch bridges having unbraced portion are greatly affected by the slenderness ratio of the unbraced portion of arch rib, in other words, the effect of the braced length ratio $\beta$ is quite significant for the ultimate strength of twin arch models having unbraced portion.

\section{(8) Axial force of lateral bracing members}

Fig. 13 shows the relation between the load and the axial strain of the diagonal and the transverse members located at the end panel of laterally braced portion. In this figure, the circles represent experimental results. The basic feature of the relation is that the axial force of diagonal members increase almost linearly from the beginning of loading and the linearity gradually disappears as the lateral deflection increases. The linear increase in the axial compressive force of diagonal members are not produced by the

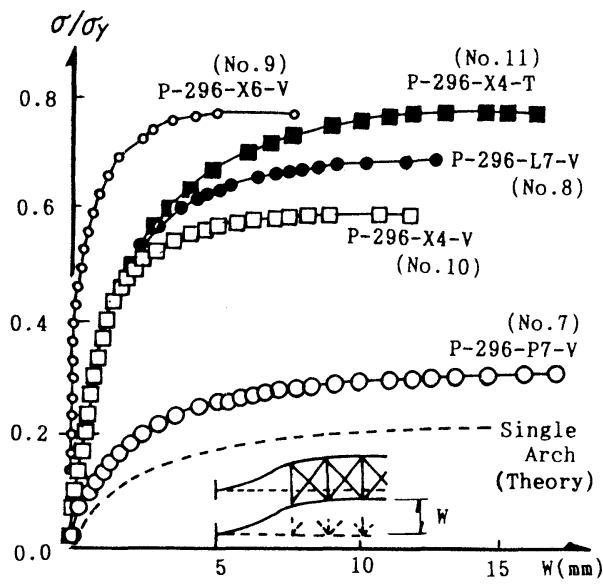

Fig. 12 Load versus Lateral Deflection Curves (Twin arches).

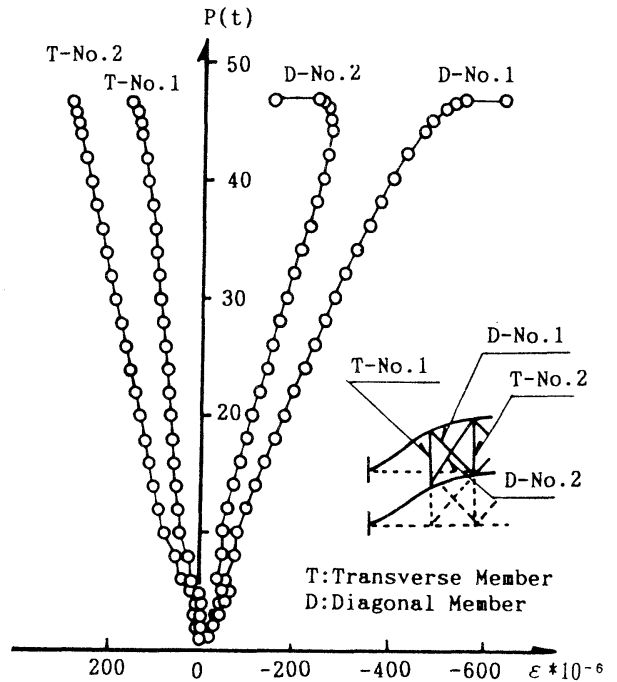

Fig. 13 Load versus Axial Strain Curves for Bracing Members (P-296-X 6-V). 
lateral deformation of the arch but by the shrinkage of the arch rib. Then, in the higher loading stage, the component of shear force produced by lateral displacement of arch ribs is added to the axial force of diagonal members. Since the lateral displacement does not increase proportionally to the load increase, the linearity gradually disappears as lateral deflection increases. That is, the axial compression force of the diagonal member No. 2 decreases and that of the diagonal member No. 1 increases nearly at 40 tons $(392 \mathrm{kN})$ of vertical load as shown in Fig. 13. On the other hand, the axial force of the transverse member is a tensile force, which is produced by the axial force of the diagonal members. It is important to point out that the axial force of diagonal members produced by the shrinkage of the arch rib is significant for proportioning diagonal members as well as the axial force caused by the design lateral load, that is, the wind load and the seismic load.

\section{(9) Lateral bending strain}

The vertical load versus lateral bending strain curves for specimen No. 10 (bracing type X 4 V) are shown in Fig. 14. The strains are measured at the end of arch rib (section 1), at the end of braced region (section 2) and at the crown of arch (section 3). It can be seen that, at the final stage of loading, large lateral bending strains are developed at the springing and the end of the braced region of arch rib in opposite sign each other. The large lateral bending strains correspond to the large lateral curvature of the arch rib. On the contrary, the strain at the arch crown stays in fairly small value, because the braced region displaces due to the rigid body motion and does not deform much. These facts correspond to the results of lateral deflection mode shown in Fig. 10. From these considerations we can have a suggestion that it is possible to increase the ultimate strength of twin arches having unbraced portion by strengthening the arch ribs in the unbraced portion.

(10) Evaluation of the ultimate strength

Fig. 15 shows the experimental results for buckling strength of arch specimens. In this figure, the ultimate strength is represented by the non-dimensionalized average normal stress $\sigma_{u} / \sigma_{y}=N_{u} / A \sigma_{y}$ (See 3 . (2)). The slenderness parameter of single arch rib, $\lambda_{y}$, is defined as follows by assuming the arch as a

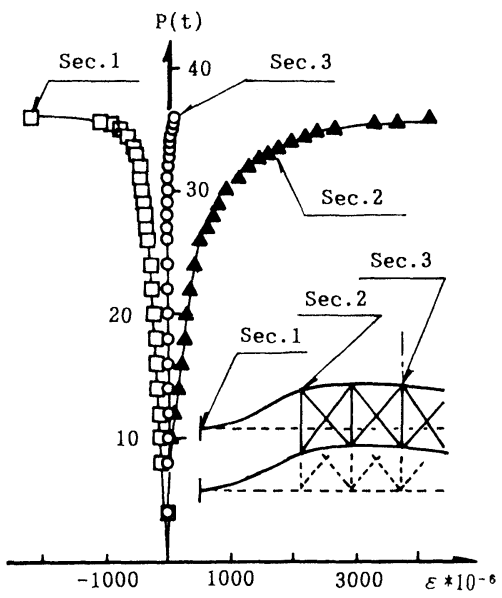

Fig. 14 Load versus Lateral Bending Strain Curves (P-296-X 4-V).

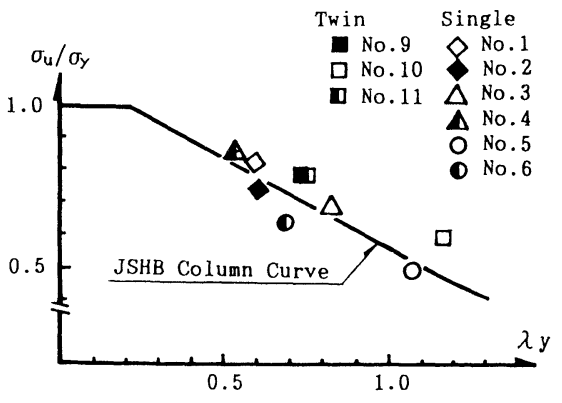

Fig. 15 Experimental Results for Buckling Strength of Model Arches.

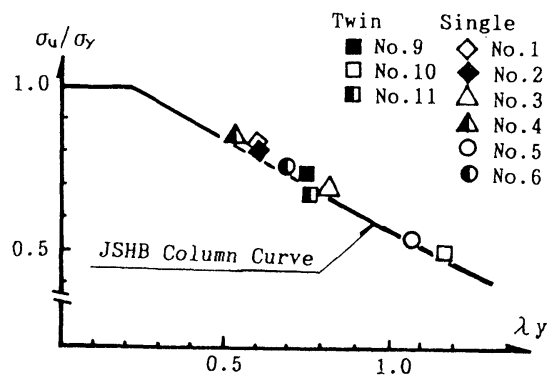

Fig. 16 Theoretical Results for Buckling Strength of Model Arches. 
clamped-clamped straight column of length $L$,

$$
\lambda_{y}=\frac{1}{\pi} \sqrt{\frac{\sigma_{y}}{E}} \cdot \frac{0.5 L}{r_{y}}
$$

where $\sigma_{y}$ is the yield point stress of the steel, $E$ stands for Young's modulus, $L$ denotes the curved length of the arch rib, $r_{y}$ is the radius of gyration of arch rib cross section with respect to out-of-plane bending. For the case of tilting load, $\lambda_{y}$ is reduced by multiplying the additional effective length factor $K_{l}=0.65$, which is determined in the previous study and accounts for the effect of tilting load. The slenderness parameter $\lambda_{y}$ for twin arch specimens, which are braced with double diagonals in combination with transverse bars, are obtained from Ref.7) which proposes a method to determine the slenderness parameter for arch bridges having closed profile cross section. That is,

$$
\lambda_{y}=\frac{1}{\pi} \sqrt{\frac{\sigma_{y}}{E}} \cdot \frac{K_{e} K_{l} K_{\beta} \cdot L}{r_{y}} .
$$

where

$K_{e}$ : effective length factor for end condition.

$K_{e}=0.5$ for laterally clamped end, $K_{e}=1.0$ for laterally hinged end.

$K_{l}$ : effective length factor counts for the effect of load direction.

$K_{l}=0.65$ for tilting load (No. 11), $K_{l}=1.0$ for vertical load (No.9, No. 10)

$K_{\beta}$ : effective length factor related to the braced length ratio $\beta$.

$K_{\beta}=1-\beta+\left\{2 r_{y}(0.5+0.94 \sqrt{\mu}) /\left(a K_{e}\right)\right\} \beta$

$K_{\beta}=0.376$ for $\beta=0.75$ (No. 9), $K_{\beta}=0.584$ for $\beta=0.50$ (No. 10, No. 11)

The derivation of these effective length factor are shown in Ref. 7). The solid line in the figure indicates the standard column strength curve specified in the Japanese Specifications for Highway Bridges.

Since the lateral deformation of the arch is characterized by the interaction between the lateral deflection and the torsional deformation, it has been expected that the buckling strength of arch member having open cross section is much smaller than the buckling strength of imaginary straight column of which slenderness parameter is given by Eq. (1). But, as can be seen from Fig. 15, the experimental results for buckling strength of single arch rib except No. 6 have good correspondence to the standard column strength curve. The experimental results of twin arches having $X$ type of bracing system are a little higher than the strength curve. On the other hand, theoretical results coincide comparatively well with the standard column strength curve as shown in Fig. 16. Judging from these results, it is suggested that the ultimate strength of a single arch member with open cross section subjected to uniformly distributed in-plane load can be approximately predicted by the buckling strength of a clamped-clamped column of length $L$ with the identical cross section.

It is also shown that the ultimate strength of the twin arches specimens having $\mathrm{X}$ type of bracing system, can be estimated approximately by the standard column strength curve utilizing the equivalent slenderness parameter for arch bridges proposed in Ref. 7). Important point is that no regard is paid for the torsional stiffness of the arch system in evaluating the lateral torsional buckling strength. In other words the lateral buckling strength of these arch models can be predicted approximately as flexural buckling of an equivalent straight column.

\section{CONCLUSIONS}

The following conclusions can be drawn from this study:

(1) The ultimate strength of a single arch member with open cross section subjected to uniformly distributed in-plane load can be approximately predicted by the buckling strength of a clamped-clamped column of length $L$ with the identical cross-section. But further theoretical investigation may be necessary to make clear the influence of torsional rigidity on the inelastic lateral buckling strength of arch member with open cross section including with different profile other than $\mathrm{H}$ sections. 
(2) The ultimate strength of arch models subjected to the tilting hanger load is quite large comparing with the case of the vertical load. The effect of load direction is also very significant for the lateral buckling strength of arch bridges. This stabilizing effect can be well evaluated by the proposed effective length factor $K_{l}=0.65$ to predict the strength by a column strength formula.

(3) The ultimate strength of arch models with twin ribs is affected considerably by the type of bracing system. That is, the bracing system which resists the lateral bending of arch ribs is more effective for increasing the ultimate strength than that which resists the torsion of arch ribs.

(4) Since the ultimate strength of the arch models having unbraced portion is greatly affected by the slenderness ratio of the unbraced portion of arch rib, the effect of braced length ratio is also very significant for the ultimate strength of twin arches having unbraced portion.

(5) The axial force of diagonal members induced by the axial shrinkage of the arch rib is quite significant for proportioning diagonal members as well as the axial force caused by the usual design lateral load.

(6) The large lateral bending occurs in the end portions of arch ribs where no lateral bracing is located, while the lateral bending moment of the arch rib in the braced portion is fairly small. It is possible to increase the ultimate strength of twin arches having unbraced portion by strengthening the arch ribs in the unbraced portion.

(7) It is shown that the ultimate strength of single rib arches and twin arches with X-type bracing system can be predicted fairly well by the formula for arches with closed cross section proposed by the writers in Ref. 7).

(8) Since the theoretical predictions show good correspondence with the experimental results, the validity of the theory is confirmed. Now, it is ready to carry out parametric studies for the ultimate strength of arch structures with open cross section by the theoretical method presented in Ref.9).

\section{ACKNOWLEDGMENTS}

This study was carried out in three years from 1986 to 1988. The writers express their appreciation and gratitude to Messrs. Kazuomi Koga, Loh Kok Choon, Toshiyuki Kobori, Giichirou Uemura and Kenji Kugimiya for their valuable help in the experiments. The writers are specially indebted to Mr. Yasuo Miyazaki, technician of the department, for his assistance in all phases of the experiments. Part of this investigation was supported by the Grant-in-aid for Scientific Research from the Ministry of Education, of which supervisor is Dr. Yuhshi Fukumoto, Prof. of Osaka university.

\section{REFERENCES}

1) Kee, C. F. : Lateral Inelastic Buckling of Tied Arches, Proc. of ASCE. Vol.87, No. ST 1. pp. 23-39, 1961.

2) Komatsu, S. and Sakimoto, T. : Ultimate Load Carrying Capacity of Steel Arches, Proc. of ASCE. Vol. 103 . No. ST 12. pp. 2323-2336, 1977.

3) Kuranishi, S. and Yabuki, T. : Effect of Lateral Bracing Rigidities on the Ultimate Strength of Steel Arch Bridges. Proc. of JSCE. No. 305, pp. 47-58, 1981 (in Japanese).

4) Sakimoto. T. and Komatsu, S. : Ultimate Strength of Arches with Bracing Systems, Proc. of ASCE. Vol. 108. No. ST 5. pp. 1064-1076, 1982.

5) Sakimoto, T. and Komatsu, S. : Ultimate Strength Formula for Steel Arches, Proc. of ASCE. Vol. 109. No. ST 3. pp. 613-627, 1983.

6) Sakimoto, T. and Komatsu, S. : Ultimate Strength Formula for Central-Arch-Girder-Bridges, Proc. of JSCE, No. 333. pp. 183-186, 1983.

7) Sakimoto, T. Tsuruta, E. and Sakata, T. : Elasto-plastic Out-of-plane Buckling Strength of Through Type and Half-through Type Arch Bridges, Journal of Structural Eng., Vol.34 A, pp. 243-254, 1987 (in Japanese).

8) Sakimoto, T., Yamao, T. and Komatsu, S. : Experimental Study on Ultimate Strength of Steel Arches, Proc. of JSCE, No. 286, pp. 139-149. 1979.

9) Sakimoto, T., Yamao, T. Kikuchi, R. and Sakata, T. : Nonlinear Analysis of Thin-walled Frames and Members with 
Arbitrary Open Cross-Section, Proc. of JSCE Structural Eng./Earthquake Eng., Vol.2, No.2, pp. 139-147. Oct. 1985. 10) Fukasawa, Y. : Buckling of Circular Arches by Lateral Flexure and Torsional under Axial Thrust, Transaction of JSCE, No. 96, pp. 29-47, 1963 (in Japanese).

11) Japan Road Association: Specifications for Highway Bridges, Feb. 1980. 